\title{
E-fast in patients with dengue infection in medical ward: a pilot study
}

\author{
A Abdul Rahim ${ }^{1 *}$, M Abd-Rahman ${ }^{1}$, SZ Zulkifli², SS Md Sani ${ }^{2}$ \\ From 10th WINFOCUS World Congress on Ultrasound in Emergency and Critical Care \\ Kuala Lumpur, Malaysia. 16-19 November 2014
}

\section{Background}

Dengue is a major tropical infection in Malaysia. It has several presentations and may progress to severe illness. Mortality is high if left unsupported. Warning Signs (WS) ; nausea, vomiting abdominal pain, bleeding and leaking syndrome (LS) (ascites and pleural effusion) are crucial in dengue assessment. Abdominal pain and tenderness, gastrointestinal bleed, jaundice, hepatomegaly and ascites are predictors of severe illness and require intensive care support as mentioned in the literatures.

At present, E-FAST is used widely in emergency unit to aid diagnosis and management in acute emergency and trauma. It has not been used in dengue infection to detect leaking syndrome. The clinical sign of leaking syndrome can be subtle if minimal. Early detection will lead to closer monitoring and anticipation of further change of clinical condition, hence aid in management of dengue.

\section{Objective}

To assess the utility of E-FAST in detecting LS in dengue infection.

\section{Patients and methods}

Cross-sectional study of patients with dengue infection admitted to medical wards in The Department of Medicine Hospital Kuala Lumpur from 18 August 2014 to 30 August 2014. All dengue infection cases received standard treatment. E-FAST was performed by a group of 4 physicians trained by WINFOCUS Malaysia Team. Each scan was performed by a physician, and reviewed by another. All baseline information, clinical and scan findings were recorded.

\footnotetext{
* Correspondence: azahira78@gmail.com

${ }^{1}$ Fellow in Acute Internal Medicine, Department of Medicine, Hospital Kuala Lumpur, Malaysia

Full list of author information is available at the end of the article
}

\section{Results}

Total of 21 patients were observed; 13 (62\%) males and 8 (8\%) females, with median age of 24 years old ( IQR 73). Median days for presentation of illness were 4 days $(I Q R$ 8). 4 (19\%) patients presented in defervescence phase and $17(81 \%)$ patients presented in febrile phase. WS were observed in all patients in this study; $3(14 \%)$ patients had $1 \mathrm{WS}, 7$ (33\%) patients had less than $3 \mathrm{WS}(<3 \mathrm{WS})$ and $11(52 \%)$ had 3 and more WS ( $\geq 3 \mathrm{WS})$. On discharge, $14(67 \%)$ patients had diagnosis of dengue fever with WS and 7 (33\%) patients had diagnosis of severe dengue.

LS were detected in total of 9 out of 21(43\%) patients. 3 out of $9(33 \%)$ patients were clinically detected by clinician versus 6 out of $9(67 \%)$ patients by E-FAST ( $p<$ 0.05). 5 patients had pleural effusion; 3 patients detected by clinician and 5 patients detected by E-FAST $(\mathrm{p}<0.05)$. 9 patients had ascites in which 1 detected by clinician and 9 detected by E-FAST $(\mathrm{p}=0.237)$. In those with LS , 8 (88\%) patients had $\geq 3$ WS compared to 1 (11\%) patients had $<3$ WS $(\mathrm{p}<0.05)$. In LS $7(78 \%)$ patients had diagnosis of severe dengue on discharge and $2(22 \%)$ patients had diagnosis of dengue fever with WS on discharge $(\mathrm{p}<0.05)$. In those with LS, $3(33 \%)$ patients needed ICU admission and $6(67 \%)$ was managed in general ward $(\mathrm{p}=0.149)$.

\section{Conclusion}

E-FAST is useful to detect fluid collection for LS in dengue patients with warning signs in Medical ward. Detection of LS is significantly better with E-FAST compare to clinical detection. Larger cohort of study population is needed for further evaluation of E-FAST usage in diagnosis, monitoring and management of dengue infection.

\section{SpringerOpen ${ }^{\circ}$}

(c) 2015 Abdul Rahim et al; licensee Springer. This is an Open Access article distributed under the terms of the Creative Commons Attribution License (http://creativecommons.org/licenses/by/4.0), which permits unrestricted use, distribution, and reproduction in any medium, provided the original work is properly cited. 


\section{Authors' details}

${ }^{1}$ Fellow in Acute Internal Medicine, Department of Medicine, Hospital Kuala Lumpur, Malaysia. ${ }^{2}$ Acute Internal Medicine Specialist, Department of

Medicine, Hospital Kuala Lumpur, Malaysia.

\section{Published: 9 March 2015}

\section{References}

1. Ahmad Nizal MG RH, Mazrura S, et al: Dengue infections and circulating serotypes in Negeri Sembilan, Malaysia. Malaysian Journal of Public Health Medicine 2012, 12(1):21-30.

2. Jamaiah I, RM, Nissapatorn V, et al: Prevalence of dengue fever and dengue hemorrhagic fever in Hospital Tengku Ampuan Rahimah, Klang, Selangor, Malaysia. Southeast Asian J Trop Med Public Health 2005, 36(Suppl 4):196-201.

3. Ooi ET, GS, Anil R, et al: Gastrointestinal manifestations of dengue infection in adults. Med J Malaysia 2008, 63(5):401-5.

4. Fadilah S, SAW, Sahrir S, Mazlam MZ, et al: A comparison of the pattern of liver involvement in dengue hemorrhagic fever with classic dengue fever. Southeast Asian J Trop Med Public Health 2000, 31(2):259-63.

5. Norlijah O, KN, Kamarul AR: Clinico-laboratory profile of dengue haemorrhagic fever in Malaysian children. Asian-Oceanian Journal of Pediatrics and Child Health 2004, 3(2).

6. Rozycki GS, Pennington Scott D., Feliciano David V: Surgeon-Performed Ultrasound in the Critical Care Setting: Its Use as an Extension of the Physical Examination to Detect Pleural Effusion. Journal of Trauma-Injury Infection \& Critical Care 2001, 50(4):636-42.

7. Bouhemad Bélaïd, MZ, Lu Qin, Rouby Jean-Jacques: Clinical review: Bedside lung ultrasound in critical care practice. Critical Care 2007, 11(205)

doi:10.1186/2036-7902-7-S1-A26

Cite this article as: Abdul Rahim et al:: E-fast in patients with dengue infection in medical ward: a pilot study. Critical Ultrasound Journal 20157 (Suppl 1):A26.

\section{Submit your manuscript to a SpringerOpen ${ }^{\mathcal{O}}$ journal and benefit from:}

- Convenient online submission

- Rigorous peer review

- Immediate publication on acceptance

- Open access: articles freely available online

- High visibility within the field

- Retaining the copyright to your article

Submit your next manuscript at $\gg$ springeropen.com 